\title{
Hipocrisia ou expiação moral? Representações de religiosidades na dramaturgia rodrigueana
}

Recebido em: 17/09/2018

Aceito em: 09/01/2019

Resumo: A obra de Nelson Rodrigues, contos, crônicas e peças, é marcada por temas como sexo, traição, incesto, enfermidades, assassinato, loucura e suicídio. É principalmente pelos opostos complementares, amor e morte, que seus personagens incorrem no trágico, não sem antes apelarem a ou demonstrarem uma prática religiosa como forma de expiação moral ou por hipocrisia. Ademais, a formação cristã do autor e os princípios morais que norteavam aquela sociedade brasileira das décadas de 40, 50 e 60, quando suas peças foram escritas, estão presentes nos seus textos e são determinantes para o logro de diversos personagens. Desse modo, o presente artigo tem por objetivo analisar a representação de religiosidades na dramaturgia rodrigueana em suas diferentes fases. Para esse fim, serão examinadas a peça mítica Álbum de familia (1945) e a tragédias carioca Boca de ouro (1959). Outros textos dramatúrgicos e não dramatúrgicos do escritor também são eventualmente cotejados com as peças escolhidas.

Palavras-chave: Nelson Rodrigues; religiosidades; peça mítica; tragédias cariocas

Abstract: The works of Nelson Rodrigues, short stories, newspaper columns and plays, are marked by themes such as sex, betrayal, incest, diseases, murder, madness and suicide. It is mainly by the complementary opposites, love and death, that his characters are subject to the tragic, not before appealing to or demonstrating a religious practice as a means of moral purge or hypocrisy. Moreover, the writer's christian upbringing and the moral principles which guided Brazilian society in the 40's, 50's and 60's, when his plays were written, are present in his texts and are decisive to several characters' misfortune. Therefore, this article aims at analysing the representation of religiosities in Rodrigues' drama in its different stages. To this end, the mythical play Family Album (1945) and the carioca tragedy Golden mouth (1959) will be examined. Other dramatic and nondramatic texts by Rodrigues are occasionally compared with the plays chosen.

Keywords: Nelson Rodrigues; religiosities; mythical play; carioca tragedies

\section{Introdução}

Toda família tem um momento que começa a apodrecer². Nelson Rodrigues

Desde quando era jornalista iniciante Nelson Rodrigues já escrevia contos, crônicas e críticas, além de reportagens policiais, para os jornais A Manhã, Crítica e O Globo, entre

\footnotetext{
${ }^{1}$ Graduação em Artes Cênicas com habilitação em Teoria do Teatro na UNIRIO (Universidade Federal do Estado do Rio de Janeiro) em 2004. Pós-graduação lato sensu em Literatura, Arte e Pensamento Contemporâneo na CCE/PUC - Rio entre 2007 e 2008. Mestre em Letras (Estudos de Literatura Brasileira), pela PUC -Rio, em 2012 e Doutora em Literatura, Cultura e Contemporaneidade, pela PUC-Rio, em 2016.. Entre agosto de 2015 e fevereiro de 2016 realizou estágio de Doutorado no departamento de Theatre Arts and Performance Studies da Brown University com Bolsa Sanduíche da CAPES. Atua como professora e pesquisadora de teatro.

${ }^{2}$ Fala do personagem Peixoto na peça Bonitinha, mas ordinária.
} 
1928 e 19353. Um desses contos, “A paixão religiosa de Maria Amélia”, escrito em julho de 1930, um mês antes de completar 18 anos, inicia com o narrador contando, a provavelmente um repórter de polícia, como cometera o assassinato:

- Apunhalei-a à altura do peito. Foi um golpe só. Maria Amélia caiu imediatamente, quase fulminada, sem um gemido, sem uma contorção. O episódio sangrento teve por teatro o interior de uma igreja. Prenderam-me logo. Aliás, eu não tentei fugir. A polícia encontrou-me a beijar, com delírio, o cadáver. Passei doze anos na cadeia. Saí ontem...(RODRIGUES, 2004, p. 124).

A partir de então, o narrador volta ao tempo e fala de como seu amor contemplativo por Maria Amélia, mulher de beleza "pura, imaterial, como a beleza das freiras" (RODRIGUES, 2004, p. 125) passou a amor carnal, tornando-lhe um "homem odioso, depravado, movidos por influências de apetites baixos, de impulsos sádicos, de instintos primitivos, bárbaros" (RODRIGUES, 2004, p. 127). Quando ainda não desejava Maria Amélia, relata que uma vez se escondeu no quarto da amada e a viu sacrificar-se:

Com um sorriso feroz nos lábios, uma chama de loucura nos olhos, ela empunhou um instrumento odioso, que eu não tinha visto ainda. Era um ferro em brasa. (...) Maria Amélia, sádica e masoquista, aplicou, sobre os seios, quase infantis, a ponta de fogo. Escancararam-se imediatamente, nessas duas rosas de carne, mal desabrochadas, as bocas rubras de duas feridas fumegantes. (RODRIGUES, 2004, p. 126)

Essa cena deixou-o apavorado. Entretanto, um ano depois, quando a viu novamente, com corpo e seios mais volumosos e "uma boca de primavera sedenta de amor" (RODRIGUES, 2004, p. 127), passou a desejá-la, embora, agora, os martírios a que Maria Amélia continuava se impondo não eram mais um espetáculo apenas atroz: "O quadro pungente, que se apresentava aos meus olhos, produzia, em mim, uma alegria feroz, inconcebível" (RODRIGUES, 2004, p. 128). Até que, certo dia, aproximou-se dela e enterrou um punhal em seu peito.

Esse conto que, segundo o próprio Nelson (RODRIGUES, 2004, p. 37), foi fruto de pesquisa sobre um assassinato realizada na Biblioteca Nacional, já contém tanto os aspectos do trágico que permeariam a obra do escritor quanto elementos que ele usaria em crônicas e peças. Além do recurso do flashback, alguns elementos que se tornariam recorrentes em sua escrita aparecem em "A paixão religiosa de Maria Amélia". A beleza punida de Maria Amélia é análoga à beleza tomada pelas chagas de Doroteia, os seios feridos pela brasa, podem nos remeter ao câncer no seio de Glorinha, de $A$ falecida, da mulher de Herculano e da própria obsessão de Geni, de Toda nudez será castigada, ou dos seios riscados de navalha, da Geni de Asfalto Selvagem. Também a adolescente Sônia, de Valsa no. 6, foi assassinada com um punhal, enquanto tocava a peça de Chopin, por Dr. Junqueira, seu médico, homem muito mais velho que ela e casado. E, enquanto o narrador é flagrado pela polícia quando beijava a já morta Maria Amélia, Arandir, de $O$ beijo no asfalto, é visto pelo repórter Amado Ribeiro beijando um homem agonizante que acabara de ser atropelado e que lhe suplicara seu último desejo.

Embora vários elementos, temas e personagens-caricatura atravessem toda a obra rodrigueana, podemos afirmar que o amor e a morte são os opostos complementares presentes e determinantes na escrita hiperbólica de Nelson Rodrigues e que implicam, geralmente,

${ }^{3}$ Alguns desde textos foram selecionados por Caco Coelho e publicados em O baú de Nelson Rodrigues (RODRIGUES, 2004).

https://periodicos.unifap.br/index.php/letras

Macapá, v. 8, n. 3, $2^{\circ}$ sem., 2018 
na tragicidade dos personagens. Segundo o próprio escritor, “Toda a minha obra é uma meditação sobre o amor e sobra a morte" (RODRIGUES apud MAGALDI, 1992, p. 21). Também a ideia da expiação da culpa e do pecado, seja por conta de um adultério, incesto ou sexo e desejo fora do casamento, através da religiosidade, culminando na morte ou na loucura presente no conto, permeia os textos dramatúrgicos e não dramatúrgicos do escritor.

A obra rodrigueana possui uma visão romântico-cristã do sexo como inseparável do amor ${ }^{4}$. Daí que nos seus textos o adultério e o sexo casual apontam para o trágico, através da ruína moral do personagem que ou morre de alguma enfermidade, é assassinado ou se suicida. Desse modo, o objetivo aqui é analisar de que forma a religiosidade é representada por Nelson Rodrigues em duas peças de dois momentos distintos: a peça mítica Álbum de familia (1945) e a tragédia carioca Boca de ouro (1959).

Percebe-se nas peças, contos e crônicas rodrigueanas uma escrita que carrega nas tintas da tragicidade, embora o cômico ou o grotesco também estejam presentes. Esse tipo de escrita atravessa toda a sua obra e poder-se-ia argumentar que toda a sua vida fora também caracterizada por acontecimentos trágicos, como o assassinato de seu irmão Roberto, na redação do jornal em que trabalhavam e que, segundo o próprio dramaturgo, marcou sua vida e sua escrita. No entanto, não se procura aqui cotejar a obra do autor com sua biografia, mas examinar, no próprio estatuto do texto e da obra, como a religiosidade é trabalhada pelo autor.

\section{1 Álbum de família}

Uma família de personagens arquétipos, ao transgredir padrões morais e regras sociais, faz de Álbum de família uma representação de uma sociedade patriarcal desintegrada.

A peça inicia com um fotógrafo, em 1900, preparando um casal para a foto do dia seguinte ao casamento. Jonas, de 25 anos, descrito pelo dramaturgo na lista de personagens como assemelhado a Jesus ${ }^{5}$, é o patriarca da família, casado com sua prima de 15 anos, D. Senhorinha, em uma referência mais explícita à Nossa Senhora. A apresentação do casal é feita pelo personagem Speaker, "uma espécie de Opinião Pública” (RODRIGUES, 1991 b, p. 54) conforme a rubrica. Desse modo, cabe ao Speaker não somente a função de narrar as cenas, mas comentá-las, muitas vezes de forma irônica:

Partem os românticos nubentes para a fazenda de Jonas, em São José de Golgonhas. Longe do bulício da cidade, gozarão a sua lua de melzinha. Good-bye, Senhorinha! Good-bye, Jonas! E não esquecer o que preconizam os Evangelhos: “Crescei e multiplicai-vos!” (RODRIGUES, 1991 b, p. 55)

Vinte anos depois, Jonas e D. Senhoriha são pais de Guilherme, Edmundo, Glória e Nonô. Glória, a caçula de 15 anos, descrita como muito parecida com a mãe, fora enviada a um colégio interno como forma de manter à distância o desejo carnal que o pai tinha pela filha. No colégio, é com a colega de dormitório que Glória conhece seu logro. A rubrica da cena a seguir indica uma sensualidade entre as duas, "ambas em finíssimas camisolas, muito

\footnotetext{
${ }^{4}$ Como assinala o crítico Sábato Magaldi, "Tendo recebido formação cristã da classe média urbana brasileira, o dramaturgo preservou até o fim da vida a crença na divindade e em preceitos morais básicos” (MAGALDI, 1992, p. 67).

${ }^{5}$ Não deve ser coincidência a escolha do nome do personagem iniciando com a letra J e tendo cinco letras, além ser também um personagem bíblico.
} 
Teresa: Juro por Deus...

Glória: Juro por Deus...

Teresa: ... que não me casarei nunca...

Glória: ... que não me casarei nunca...

Teresa: ... que serei fiel a você até à morte.

Glória: ... que serei fiel à você até a morte.

Teresa: E que nem namora.

Glória: que nem namoro.

Teresa: (apaixonada) Também juro por Deus que não me casarei nunca, que só amarei você, e que nenhum homem me beijará. (...)

Teresa: Mas não quero que você morra, nunca! Só depois de mim! Ou então ao mesmo tempo, juntas. Eu e você enterradas no mesmo caixão. (RODRIGUES, 1991b, p. 55).

As duas então se beijam. Posteriormente nos é revelado que o amor lésbico das jovens moças foi punido com a expulsão de Glória.

Além da tentativa de Jonas de manter a filha à distância, o personagem também compensava o desejo por Glória através de relações sexuais com adolescentes, conforme o próprio explica: "Gosto de menina sem-vergonha. Mulher não, menina. De 14, 15 anos" (RODRIGUES, 1991b, p. 61). Algumas dessas moças eram-lhe entregues por familiares, como pode ser visto na cena em que um avô traz a neta para a Jonas, explicado pela rubrica: “... acaba de entrar o avô da nova conquista de Jonas. Um velho de barbas bíblicas"(RODRIGUES, 1991b, p. 60). Durante grande parte da peça, são ouvidos gritos de uma moça; tratase de uma das vítimas de Jonas em trabalho de parto. Da sala onde esses gritos são ouvidos, há, conforme rubrica, um retrato de Jesus na parede.

Se a maneira encontrada por Jonas para compensar seu desejo por Glória foi enviá-la a um colégio interno e manter relações sexuais com moças da mesma idade da filha, Guilherme se puniu pelo mesmo desejo carnal pela irmã com a castração e decisão de se tornar padre. Entretanto, quando Glória retorna à casa da família, Guilherme abandona o seminário para proteger a irmã do pai e sugere, quando vão a uma igrejinha, que fujam de casa. Essa igreja é descrita na rubrica a partir do que seria a mente de Glória:

Retrato imenso de Nosso Senhor, inteiramente desproporcionado - que vai do teto ao chão. NOTA IMPORTANTE: em vez do rosto do Senhor, o que se vê é o rosto cruel e bestial de Jonas. É evidente que o quadro, assim grande, corresponde às condições psicológicas de Glória, que vem entrando com Guilherme. Primeira providência de Glória: olhar para a falsa fisionomia de Jesus"(RODRIGUES, 1991b, p. 96)

Além de ver a fisionomia do pai na figura de Jesus, ao contrário de Guilherme, que não vê semelhança alguma entre os dois, Glória deixa entrever o amor erótico que sente pelo pai ao explicar para o irmão o beijo que deu na colega Teresa, motivo de sua expulsão do colégio: "toda vez que a gente se beijava, eu fechava os olhos e via direitinho a fisionomia de papai. Mas direitinho como está ali’(RODRIGUES, 1991b, p. 97).

Também Edmundo retorna ao lar após se separar da esposa. Segundo Heloísa, "Quando queria, e me procurava, a lembrança da"outra" IMPEDIA! Então, ele me dizia: “Heloísa, 'Ela' não me deixa!"”(RODRIGUES, 1991b, p. 98). Assim, descobrimos que ao longo de mais de três anos de casamento Edmundo e Heloísa jamais tiveram relação sexual e D. Senhorinha, para quem Edmundo era uma "santa" (RODRIGUES, 1991b, p. 83) é, na verdade, fruto do seu verdadeiro desejo sexual. 
Edmundo odeia o pai por tratar mal D. Senhorinha enquanto Guilherme também não suporta o pai pelo mesmo motivo e pelo amor à Glória. Jonas também odeia os filhos Edmundo e Guilherme, mas não admite o contrário: "Mas Eles estão enganados comigo. Eu sou o PAI! O pai é sagrado, o pai é o SENHOR! (fora de si) Agora eu vou ler a Bíblia, todos os dias, antes de jantar, principalmente os versículos que falam da família!” (RODRIGUES, 1991b, p. 72).

Glória e D. Senhorinha também se odeiam mutuamente. Por outro lado, D. Senhorinha demonstra preferência por Nonô, o filho mais novo descrito como "doido", "maluco", que vive gemendo e andando nu pelo mato, enlouqueceu após ter tido relação sexual com a mãe.

Em Álbum de família os personagens se amam e se odeiam; todos cometeram algum desvio moral e, por isso, foram passíveis de punição. Nem Tia Rute, irmã de D. Senhorinha escapou, pois permaneceu solteira e sem atributos físicos após ter tido relação sexual com o cunhado. Como assinala Sábato Magaldi a respeito da dramaturgia rodrigueana, "A morte raramente é natural. A violência comparece à quase totalidade dos desfechos trágicos..." (MAGALDI, 1992, p. 22). Album de família é uma das peças escolhidas pelo crítico para exemplificar tal assertiva. Dessa forma, explica Magaldi:

Em Álbum de família são numerosas as mortes violentas: uma menina grávida falece durante o espetáculo, em dores do parto, sem que receba socorro médico (outra menina de 15 anos, engravidada por Jonas, havia morrido, enquanto Guilherme pisoteou no ventre, até matar, uma muda e estrábica, seduzida pelo pai; Jonas matou o jornalista que D. Senhorinha mentiu ser o vulto que fugia do seu quarto (...); Guilherme assassina a irmã Glória, para que não pertença ao pai Jonas, e se joga, a seguir, entre os vagões de um trem; Edmundo suicida-se na frente da mãe D. Senhorinha; e Senhorinha acaba por atirar no marido Jonas"(MAGALDI, 1992, p. 22).

A religiosidade em Álbum de família é exercida de forma a camuflar o que seria considerado desvios morais, desde relação sexual fora do casamento até o incesto. Nas próprias rubricas, descrições de objetos de cena e cenário, além da caracterização e diálogo dos personagens Nelson Rodrigues procurou aproximá-los de elementos bíblicos. A religiosidade, entretanto, não é exercida pelos personagens de forma a obterem algum tipo de perdão ou redenção, mas é trabalhada pelo dramaturgo com o objetivo de mostrar a hipocrisia daquele núcleo familiar e como metáfora da degeneração da sociedade patriarcal brasileira.

\section{Boca de ouro}

O protagonista Boca de ouro, bicheiro e morador de Madureira, filho de uma prostituta que frequentava uma gafieira chamada "Imperadores da Floresta", nasceu na pia do banheiro da gafieira e, embora diga se sentir honrado por isso e chame a mãe de "A Virgem de Ouro" (RODRIGUES, 1990a, p. 288), humilha as grã-finas que lhe perguntam sobre a história de seu nascimento em um concurso para ver qual delas teria os peitos mais bonitos.

Maria Luísa, uma dessas grã-finas, diz que foi durante sua dieta que teve uma visão. Ao ser perguntada por Boca de ouro se era espírita, a grã-fina se mostra chocada e afirma ser católica, assegurando que teve uma visão do Cristo, e se desculpa com Celeste, amante do protagonista: "Se eu te humilhei no colégio, te peço perdão, de joelhos! (...) E eu senti que devia viver para Deus e que... (...) Muito engraçado, o meu marido! Diz que a minha igreja é dietética! (RODRIGUES, 1990a, p. 332).

Mais adiante na peça, Boca de ouro sugere que a grã-fina tenha "bossa pra santa" 
(RODRIGUES, 1990a: 332), pois ela está prestes a entrar para uma ordem onde deve ter a cabeça raspada. Ao ser interpelado por Celeste, que suspeita que Maria Luísa fora até a casa de seu amante com fins sexuais, Boca de ouro explica: "D. Maria Luísa vem aqui porque quer me batizar! Pronto, quer me batizar! E, até, já me levou a uma igreja, bonita pra chuchu!" (RODRIGUES, 1990a. p.333) mas também adverte: "Só que esse negócio, Madame, é que estou meio na dúvida... (começa a rir como uma criança grande) Sou meio macumbeiro..." (RODRIGUES, 1990a. p.333-334).

Essas mulheres, caricaturizadas por Nelson sob a alcunha pejorativa de "grã-finas" ou "granfas" são afetadas, usam estrangeirismos como "boutade" (RODRIGUES, 1990a. p. 302), "Bye", "So long" e "Chau" (RODRIGUES, 1990a. p.306), se referem ao caixão de ouro do protagonista como "coisa de um deus asteca" e a ele próprio como "meio neorealista", um tipo que "o De Sica ia adorar" (RODRIGUES, 1990a, p. 300). Até em uma rubrica as grã-finas são mostradas como detentoras de uma "frívola e alegre comicidade" (RODRIGUES, 1990a. p.300). O modo sarcástico e humilhante pelo qual o protagonista trata essas mulheres diz respeito a uma frustração com sua origem humilde. Como assinala Adriana Facina,

essa possibilidade de interação entre indivíduos de diferentes classes, profissões, raças e credos religiosos que os espaços públicos da cidade oferecem são fundamentais nas representações sobre o Rio de Janeiro elaboradas por Nelson Rodrigues. Não se trata, porém, de uma visão de relações sociais harmoniosas, ou democráticas e igualitárias" (FACINA, 2004, p. 189).

Boca de ouro, em contraposição à origem humilde, planejava um enterro de luxo, com um caixão de ouro. A vida de pobreza do protagonista foi simbolizada pelo ouro, pois não só o caixão seria feito desse material, como ele conta para o dentista que desde garotinho sonhava em ter uma boca de ouro. Ele chega a acreditar que estaria imune à morte enquanto não tivesse juntado todo o ouro suficiente para o caixão. Certamente vingando sua origem através das personagens gra-finas, Nelson Rodrigues faz do protagonista um dos seus célebres personagens-tipo, o canalha. Desse modo, Boca de ouro diz a Maria Luísa que jogará os cadáveres de Leleco e de Celeste nas matas da Tijuca, "Na Tijuca, ponho um cadáver em cima do outro... (mais sórdido) A mulher por baixo, naturalmente" (RODRIGUES, 1990a, p. 336), quando faz Maria Luísa beijá-lo, depois de dizer "Beija o teu assassino" (RODRIGUES, 1990a, p.335) e quando humilha as três grã-finas durante o concurso de seios, além de enxotá-las de sua casa depois.

Já no fim da peça, o Locutor da Rádio Continental, descrito na rubrica como "um tipo bem característico, (...) com uma ênfase quase caricatural e uma adjetivação pomposa e vazia” (RODRIGUES, 1990a, p.290), comenta sobre a morte do protagonista:

... Mataram o "Boca de Ouro", o Al Capone, O Drácula de Madureira, o D. Quixote do jogo do bicho, o homem que matava com uma mão e dava esmola com a outra! Uma multidão, uma fila dupla que se alonga, que serpenteia, que ondula, da Presidente Vargas até o pátio do necrotério. São homens, mulheres e até crianças. Até crianças que vêm olhar, pela última vez, essa estrela do crime que foi "Boca de Ouro"! Ouvintes da Continental, é uma apoteose fúnebre nunca vista!... (RODRIGUES, 1990a, p.337)

Boca de ouro projetava no enterro a compensação de uma vida de frustrações, principalmente a de ter nascido de uma prostituta em uma pia de gafieira. A dentadura de ouro 
e o plano de ser enterrado em um caixão também de ouro materializavam as frustrações pessoais do personagem. No entanto, não teve o enterro desejado, pois morrera antes que a construção do caixão fosse concluída e ainda teve como plateia toda a população que fora ver seu cadáver e se deparou com uma boca desdentada.

O tratamento dado às religiosidades em Boca de ouro resvala mais para o cômico, conforme pode ser observado na relação que a grã-fina faz com o catolicismo e sua dieta, o modo como o protagonista se refere a si como "macumbeiro", ou a narração do enterro na rádio. Podemos perceber aqui também as duplas antitéticas que povoam as tragédias cariocas, zona sul x zona norte e subúrbio, através não apenas dos estereótipos grãfinas x bicheiro, como católicas x macumbeiro.

\section{Considerações finais}

Em 1928 Nelson escreveu um conto sobre Kalypsus Lucy, mulher descrita como "febril, convulsa; porque suas palavras eram vertiginosas, epilépticas, desconexas" (RODRIGUES, 2004, p. 88), aparentemente uma prostituta que o escritor conhecia. O conto é a memória do autor dessa mulher que acabara de morrer, "às duas tarde, quando dizia, abatida e humilhada, que desejava a morte, porque a morte era a única vontade sobrevivente, o único mistério intacto" (RODRIGUES, 2004, p.87).

Assim como Kalypsus Lucy, em Álbum de família, em Boca de ouro a morte era a única possibilidade para os personagens que agiam de encontro 'a moral vigente e aos preceitos cristãos, seja como suicídio ou assassinato. Flora Sussekind percebe, na dramaturgia rodrigueana,

uma abordagem crítica da estrutura social brasileira, cujo sistema de relações e cujos valores de base têm sua aparente segurança abalada. Para os que violam as regras dessa estrutura as saídas normalmente delineadas em suas peças são a morte e/ou loucura, ou seja, uma exclusão possibilitada por esse mesmo sistema social" (SUSSEKIND, 1977, p. 13).

Ao pôr em xeque o imaginário social de família e matrimônio, através de histórias de desejos sexuais proibidos, reprimidos ou extravasados, tanto nas crônicas quanto nas peças míticas e tragédias cariocas, Nelson mostra, muitas vezes através de uma pretensa religiosidade de seus personagens, como a modernização das cidades e da vida urbana, e sua consequente mudança nos padrões de comportamento, acenaram com o abalo das estruturas da família patriarcal.

\section{Referências}

FACINA, Adriana. Santos e canalhas: uma análise antropológica da obra de Nelson Rodrigues. Rio de Janeiro: Civilização Brasileira, 2004.

MAGALDI, Sábato. Introdução. In: Teatro Completo: peças psicológicas. Rio de Janeiro: Nova Fronteira, 1981.

Nelson Rodrigues: dramaturgia e encenações. São Paulo: Perspectiva, 1992. RODRIGUES, Nelson. O Baú de Nelson Rodrigues: os primeiros anos de crítica e reportagem (1928 - 1935) São Paulo: Companhia das Letras, 2004.

Teatro Completo: peças psicológicas. Rio de Janeiro: Nova Fronteira, 1981a.

Teatro Completo: peças míticas. Rio de Janeiro: Nova Fronteira, 1981b.

https://periodicos.unifap.br/index.php/letras

Macapá, v. 8, n. 3, $2^{\circ}$ sem., 2018 

$1990 \mathrm{a}$

Teatro Completo: tragédias cariocas I. Rio de Janeiro: Nova Fronteira,

Teatro Completo: tragédias cariocas II. Rio de Janeiro: Nova Fronteira, 1990b.

SUSSEKIND, Flora. Nelson Rodrigues e o fundo falso. In: I Concurso Nacional de Monografias - 1976. Brasília, Ministério da Educação e Cultura, Departamento

de Documentaçã Santos e canalhas: uma análise antropológica da obra de Nelson Rodrigues. Rio de Janeiro: Civilização Brasileira, 2004.

o e Divulgação, 1977. 